\title{
ANDALUCÍA Y JAPÓN. \\ Imaginario compartido de una relación histórica y nuevos significados en la globa- lización
}

Carmen LÓPEZ RODRÍGUEZ

Universidad de Sevilla lopezrodcarmen@gmail.com

\begin{abstract}
ANDALUCÍA AND JAPAN. Shared imaginary of a historical relation and new meanings in globalization
Resumen: Las relaciones turísticas y migratorias entre España y Japón son cada vez más importantes. En estas relaciones, lo más destacable es el goce y el consumo del patrimonio como elemento clave, estando este enfocado en el patrimonio cultural andaluz. Además de ello, el imaginario construido a partir de la relación histórica constituye una pieza esencial para la construcción de un patrimonio compartido. Este trabajo está enfocado en las relaciones históricas, las producciones culturales y la construcción del patrimonio, para acercarnos a los elementos de atracción que fortalecen estas relaciones en los flujos globales.

Abstract: The tourist and migratory relations between Spain and Japan are increasingly important. In these relationships, the most remarkable thing is the enjoyment and consumption of heritage as a key element, being this focused on the Andalusian cultural heritage. Moreover, the imaginary constructed from the historical relationship constitutes an essential piece for the construction of a shared heritage. This work focused on historical relationships, cultural productions and the construction of heritage, to approach the elements of attraction that strengthen these relationships in global flows.
\end{abstract}

Palabras clave: Patrimonio cultural. Turismo. Imaginario. Andalucía. Japón

Cultural heritage. Tourism. Imaginary. Andalusia. Japan 


\section{Introducción}

España y Japón, a pesar de su distancia tanto cultural como física, son dos naciones protagonistas de los intercambios culturales a nivel planetario. Muestra de ello, son los intercambios turísticos, e incluso migratorios, cada vez más intensos y continuos entre sus ciudadanos. Sin embargo, lo destacable y más especial de este contacto, es la importancia que tiene el patrimonio cultural en estas relaciones; pues a diferencia del contacto turístico establecido entre otros países, Japón y España comparten una "pasión por su arte", es decir, una especial consideración por su cultura y su patrimonio que está presente en la mayoría de su población. Estos dos países se caracterizan por su riqueza histórico-artística, donde el patrimonio cultural presenta un peso importante a la hora de definir su identidad y las representaciones confrontadas con el otro. Además, ambas sociedades muestran un respeto muy fuerte por el ámbito cultural y el patrimonio, sobre todo en el caso del colectivo japonés. Estos factores influyen en los flujos interculturales entre estas áreas y tienen su reflejo en las actividades para el turismo y en las migraciones; así como, en la transculturación que experimenta algunos patrimonios y productos culturales arropados por la cobertura mediática, o promovidos por los organismos internacionales que gestionan y elaboran las categorías y políticas culturales a nivel mundial como la UNESCO (Pratt, 2000; Castaño, 2018).

Por ello, el tema principal del presente articulo es estudiar el papel que juega el patrimonio cultural en las relaciones que se establecen entre japoneses y andaluces en el contexto de globalización. Con él, trato de realizar una introducción al modo en que los imaginarios compartidos tienen una influencia en el acercamiento intercultural y en el consumo de productos que circulan entre colectivos diferentes, los cuales muestran ciertas representaciones sobre andaluces y japoneses que tienen un valor a priori para los flujos comercializables en la globalización. Aunque la cultura como consumo implica entrar en otras problemáticas, la naturaleza introductoria de este tipo de trabajo me impide profundizar en ello.

Se parte de la indagación un tanto cándida de por qué los japoneses tienen un interés tan especial en Andalucía en cuánto representación potencial exótica de lo español. Esta cuestión surge de la observación de una presencia de japoneses en núcleos urbanos como Sevilla y Granada cada vez mayor y casi siempre relacionada con aspectos específicos del patrimonio cultural como son el flamenco, los monumentos o la comida. A partir de la constatación de este hecho, que forma parte de una experiencia cognoscitiva en el propio entorno al que pertenezco como andaluza, viajé a Tokio con un pre-proyecto para este trabajo, que se sustenta en la hipótesis de que el patrimonio cultural vehicula una serie de representaciones entre andaluces y japoneses que desde el contacto histórico hasta los consumos globales ha tenido influencia en una representación positiva sobre el otro, que permite a nivel de cultura de masas una interculturalidad que se mantiene en la distancia, pero que a su vez nutre los consumos turísticos y la circulación de consumibles de la industria cultural. La cuestión de base es que este presente no surge de la nada, sino de un continuum cultural histórico no suficientemente valorado, que ha establecido desde los contactos políticos de la modernidad imperial, unos referentes que si bien se han resemantizado y adaptado al presente, han permitido cierto entramado de lo exótico positivo entre las partes a considerar, que persisten en las nuevas tendencias y elaboraciones. Por tanto, el propósito principal es investigar los vínculos que han establecido y mantenido España y Japón desde la modernidad, el valor como patrimonio histórico compartido que han tomado estas relaciones en la producción de conocimiento, y la forma en que se reactivan otros patrimonios culturales que influyen en las representaciones contemporáneas construyéndose un imaginario compartido con valor en el turismo y en los flujos de intercambio cultural en la globalización. Para acercarnos a la comprobación o refutación de esta hipótesis hemos trazado unos objetivos principales para este estudio:

1. Se abordará en un principio, a través de la producción historiográfica al alcance, las relaciones históricas de naturaleza política y el encuentro cultural que van a dar lugar entre estos dos países. Desde los primeros misioneros españoles y portugueses que la historiografía documenta como el encuentro entre una civilización en expansión y una lejana cultural, se puede ilustrar de qué forma, un hecho histórico nutre buena parte de las representaciones del pasado, pero también del presente a través de las narrativas cinematográficas más consumidas (por ejemplo, Silencio dirigida por Martin Scorsese en 2016).

2. Tras el estudio de este periodo, se analizará uno de los temas claves para la investigación: el imaginario del colectivo japonés sobre España y Andalucía, el cual surge de este contacto cultural histórico y se verá influenciado por otros factores del contexto colonial moderno del s. XIX que ponen las bases genealógicas de los consumos culturales modernos del capitalismo global.

3. Se estudiará la influencia de los viajeros románticos europeos del s. XIX (orientalismo) en la construcción de la representación exótica de Andalucía, y de la noción de lo oriental como exótico. De esta manera, se intentará entender las claves contemporáneas de contextos construidos como el Parque España de 
Japón como producto cultural y turístico donde el imaginario de España y Andalucía toma nuevos sentidos en la globalización.

Con el fin de realizar una investigación extensa y profunda sobre el tema y proporcionarle un trato académico basado en las teorías e hipótesis de autores y profesionales académicos, se ha realizado una lectura y recopilación de información a través de una revisión bibliográfica. La revisión bibliográfica se ha basado en una documentación de fuentes académicas, turísticas e históricas. Han sido encontradas por medio de la búsqueda bibliográfica en las bibliotecas de la Universidad de Sevilla, en el sistema www.fama.us.es, y de la Rikkyo University de Tokio, y a través de recursos académicos como Dialnet. Entre estas fuentes, se ha utilizado material en diferentes lenguas. Por un lado, obras japonesas como la obra 日本・スペイン交 流史 (Historia de intercambios entre Japón y España) (坂東省次, 川成洋編, 2010), también en inglés, como la obra de Caddell sobre las actividades religiosas realizadas por los jesuitas en Japón The Cross in Japan: a history of the missions of St. Francis Xavier and the early Jesuits (Caddell, 1904) y en español, como las conferencias realizadas por Jesús San Bernardino (2017).

Se ha tratado de una metodología multidisciplinar ya que la documentación procede de diferentes campos de investigación académicas, destacando la antropológica, la histórica y el turismo; y se ha centrado en dos temáticas fundamentalmente. Por un lado, en las relaciones y encuentros entre las naciones de España y Japón a lo largo de la historia como la obra Japón y España: acercamientos y desencuentros (Zamora, 2012). Por otro lado, se ha realizado una búsqueda del estudio de los flujos turísticos entre España y Japón donde se estudia el imaginario construido por el colectivo japonés de España. Sobre esta temática, pueden ser señaladas entre otras la obra La imagen de Andalucía en el turismo cultural: el caso de Japón de la autora Anjhara Gómez Aragón. Además, surge una nueva búsqueda basada en la construcción del imaginario de Andalucía y España, el cual está presente en estas relaciones y que revela la influencia de la corriente romántica en esta construcción. Destacan las obras de González Troyano, La imagen de Andalucía en los viajeros románticos y homenaje a Gerald Brenan (González Troyano, 1987) y de Isidoro Moreno, Andalucía: identidad y cultura (estudios de Antropología Andaluza) (Moreno, 1993).

Con respecto a la estructura del artículo, se hablará en un principio de las relaciones históricas y el encuentro cultural entre España y Japón, con la llegada de los primeros misioneros españoles y portugueses quienes, paralelamente a sus intentos de evangelización religiosa, llevaron a cabo toda una "evangelización cultural". En este contexto, se analizará además el papel de la embajada Keicho, a través de la cual Sevilla, capital de Andalucía, tuvo un contacto directo con Japón. Tras el estudio de este periodo, se analizará el impacto de occidente en la sociedad japonesas, fruto de este contacto cultural-histórico e influenciado por otros factores de la sociedad del s. XIX. Con el fin de llegar a obtener una aproximación general de los factores que inciden en el imaginario moderno de Andalucía creado por Japón, se estudiará la influencia de los viajeros románticos europeos del s. XIX (y la influencia del orientalismo) en la construcción de la representación exótica de Andalucía. Además, se hablará de la confusa y poca distinción que se establece entre los imaginarios de Andalucía y de España, presente en el imaginario creado por el colectivo japonés. Tras estudiar todo esto, se comentará los aspectos generales del imaginario de España y Andalucía creado por Japón. Para profundizar aún más en este tema, se hablará del Parque España de Japón, que constituye un producto cultural y turístico donde el imaginario de España y Andalucía toma vida. Para finalizar se extraerán y expondrán algunas conclusiones.

\section{Contexto histórico del contacto España-Japón y el imaginario creado a partir de él}

Los primeros contactos entre estas dos naciones datan de la conocida Era de los Descubrimientos, siglos XVI y XVII, en la que el Imperio Español y la Corona Portuguesa eran los dueños del mundo colonizado debido a las grandes expediciones que llevaron a cabo. Con el Tratado de Tordesillas (1494), el mundo quedó repartido entre estas dos naciones, de tal forma que los españoles fueron dueños del Pacífico durante cuatro largos siglos. Inicialmente las motivaciones comerciales fueron la razón principal de estas naciones para surcar los mares (Bejarano, s.p. ${ }^{1}$. Con el paso del tiempo, surgieron cuestiones culturales que, unidas a las inquietudes comerciales, hicieron a los occidentales cruzar el mundo. Una de estas inquietudes fue la expansión de la religión cristiana (Torralba, 2016).

En ese momento histórico, Japón y España compartían ciertos rasgos. Ambas naciones habían sido víctimas de una época de guerras civiles que dividieron el país; en el caso de Japón, el periodo conocido como Sengoku Jidai 戦国時代 (periodo de los estados en guerra), y en España, las guerras entre los nobles españoles. Estas divisiones nacionales llegaron a su fin con la unificación del país, gracias a los Reyes Católicos en España y gracias a los Shogunes Tokugawa en Japón. Tras esta unificación, Japón redujo drásticamente

1 Material docente de la asignatura Historia Moderna de Asia Oriental del Grado de Estudios de Asia Oriental de la Universidad de Sevilla, curso 2015-2016. 
su comercio a los occidentales, por lo que fue visto como un país aislado del comercio. Este aislamiento, aunque en los últimos años y con la bibliografía consultada se ha demostrado que no fue un aislamiento completo, conllevó un desarrollo cultural artístico dentro de la comunidad japonesa. Además, España durante este periodo también experimentó un gran desarrollo cultural (Zamora, 2012). De esta manera, nos encontramos con dos naciones que ya desde el s. XVI muestran un interés especial en la cultura y en las artes.

En 1543, llegaron a las costas japoneses los primeros occidentales. Éstos fueron navegantes portugueses quienes debido a un tifón se desviaron de su ruta y llegaron a Tanegashima en las islas Ryukyu, al sur de Japón. Los japoneses quedaron impactados por estos extranjeros y sus armas de fuego por lo que mostraron interés en mantener el contacto con estos nuevos visitantes (Zamora, 2012: 24):

"Los galeones de Manila [...] unían Manila y Acapulco con regularidad, y México y España estaban sólidamente unidas por los galeones de las Indias que terminaban sus viajes en el puerto de Sevilla "Nueva Roma" según unos y "Nueva Babilonia" según otros [...] España y Portugal volvían a encontrarse, esta vez en los mares de China y Filipinas. Los españoles con base en Manila [...] enviaban sus barcos al sur de Japón. Y allí, la rivalidad entre España y Portugal se traducía incluso en una competencia ente los jesuitas, prolusos y los franciscanos...".

Como consecuencia, pronto se establecieron dos rutas que unían Occidente con Japón. Una de ellas, la portuguesa que recorría los puertos de Lisboa, Goa, Malaca y Macao llegando finalmente a Nagasaki. Y la otra, la española, que partía de Sevilla y recorría las colonias de Veracruz, Acapulco y Manila (Torralba, 2016).

De esta manera, cinco años después de la llegada de los portugueses, el rey Manuel I ordenó el envío de misioneros de la Compañía de Jesús con el fin de expandir la religión cristiana (Zamora, 2012). El primero de ellos, clave de nuestra investigación en este primer apartado, fue el jesuita navarro Francisco Javier ${ }^{2}$ (1506-1552). El viaje que emprendió este monje jesuita comenzó en 1549 recorriendo la ruta portuguesa de Lisboa, Goa, Macao y por último, Japón. Fue en Maracas (India) donde conoce a Yajirou, un japonés del que se hace amigo y con el que emprenderá el viaje a Japón, siendo éste su traductor. El 15 de agosto de 1549 llega a la isla artificial de Hirado, en la prefectura de Nagasaki, conocida como Dejima 出島 (isla de salida), una isla construida para mantener el contacto con el exterior durante el supuesto aislamiento japonés de esa época (坂東省次, 川成洋編, 2010). Tras llegar a Japón, Francisco Javier comprobó que los japoneses no eran como el resto de comunidades que había visitado y se percató de su alto nivel cultural. Por ello, decidió llevar a cabo una evangelización a través del patrimonio cultural español y portugués, es decir, una evangelización cultural (García Gutiérrez, 2014). De esta manera, presentó muchas obras artísticas cristianas a los señores feudales japoneses. Uno de ellos, fue el shogun Nobunaga (1534-1582) quien mostró un particular interés por lo exótico y como consecuencia, por la cultura occidental. Tal fue su interés, que permitió a los cristianos establecerse en el reino japonés. Se vio influenciado por el arte que los evangelistas traían y ordenó la construcción de un castillo de planta octogonal, alejado de la tradición japonesa. Además, poseía diferentes objetos cristianos, como un rosario que utilizaba como complemento de ropa (Zamora, 2012).

A pesar de los logros del misionero jesuita Francisco Javier, el evangelista tuvo que volver a la India donde murió (Caddell, 1904), por lo que fue reemplazado por otros jesuitas y eclesiásticos. Tras la misión de Francisco Javier, fueron muchos los misioneros jesuitas y franciscanos que viajaron a Japón, de los cuáles algunos crearon crónicas imprescindibles para el estudio del Japón del s. XVI y sus artes. Entre muchos, destacó el jesuita Alessandro Valignano (1539-1606) quien escribió Sumarios de las cosas del Japón, donde hablaba de las diferentes ventajas e inconvenientes que presentaba la evangelización de la sociedad japonesa según este jesuita. En este libro relataba la Consulta de Usuki de 1580 mediante la cual Valignano presentó "los principios que amenazaban la ruina de la Compañía en Japón". Uno de ellos fue la forma de gobierno japonesa ya que propiciaba muchos problemas para la adaptación de la cristiandad. Además, relataba los encuentros con Diego Hibiya, Don Pablo Miki, y Don Simón Tawara Chikatora, japoneses cristianizados y con nombres españoles. Por último, narraba su visita a Nobunaga a quien le explicó el viaje que hicieron desde Europa (Valignano, 1583: 346):

"Esto es, muy Reverendo Padre nuestro, lo que me ocurrió decir en este Sumario o Tratado de Japón, de lo cual todo podrá Vuestra Paternidad entender cuán grande y fructuosa es esta

2 Este jesuita fue canonizado en el año 1622, años después de los hechos narrados. Por ello, y atendiendo al sentido colonial, orientalista y eurocéntrico que se contiene en la aplicación del apócope de santidad antecediendo a su nombre cuando se refieren hechos históricos que se recogen de su actividad en vida, hemos optado por suprimirlo en este trabajo, en aras de una mayor objetividad, que no neutralidad. 
empresa y cuán necesitada y peligrosa y cuán a su cargo la debe tomar Vuestra Paternidad, cuya vida guarde nuestro Señor, para Su servicio y bien de la Compañía, por muchos años".

A pesar de las pocas esperanzas por la cristiandad en Japón que mostraba este personaje en su libro, en 1582 Valignano dirigió la primera embajada japonesa hacia España y Europa (Zamora, 2012). Su primera visita fue en Lisboa donde conocieron a un sacerdote de Granada. Tras ello, fueron a Badajoz donde visitaron la catedral de Guadalupe, famosa por sus peregrinos, y Toledo. La embajada no se sorprendió por la arquitectura de las catedrales y los monumentos pero sí mostró mucho interés en relojes y otros elementos tecnológicos. Tras Toledo, se dirigieron a Madrid donde permanecieron un mes. Allí, visitaron a Felipe II (1527-1598) quien mostró un gran interés en los kimonos y en la forma de escribir japonés. Por otro lado, los japoneses se sorprendieron de nuestro poder fiscal y nuestras artes. Tras estar en Madrid, visitaron también Cuenca, Murcia, Elche y Alicante. En el puerto de Alicante, partieron a Italia donde pasaron una temporada en Roma y volvieron a Japón desde España (川成洋 坂東省次編, 2006). A pesar del gran enriquecimiento cultural que conllevó esta embajada, el objetivo de favorecer la presencia jesuita en Japón no tuvo mucho éxito debido a los sucesos posteriores que ocurrieron en Japón (Zamora, 2012).

Estos años constituyeron un periodo de inestabilidad con las potencias occidentales. En Japón, existía el miedo de ser conquistados fomentado por el aumento de la presencia occidental. Por un lado, se optaba por una alianza con los católicos de los países ibéricos y por otro, una alianza con los holandeses quienes persuadieron a los mandatarios japoneses de no confiar en los imperios ibéricos por sus intenciones conquistadoras. Por ello, se crearon embajadas para comprobar la alianza con unos países u otros (San Bernardino, s.p. $)^{3}$. Con la llegada de Hideyoshi (1537-1598) al poder, comenzaron las persecuciones de los cristianos ya que éste optó por confiar en los holandeses y reducir la apertura comercial sólo para ellos, iniciando así el conocido aislamiento de Japón de esta época. Las relaciones entre España y Japón terminaron en 1596 con el suceso de Nagasaki en el que unos evangelistas enviados desde España y algunos japoneses convertidos al cristianismo fueron crucificados por ser cristianos y por sus supuestas intenciones de colonizar Japón. Los mártires de este suceso fueron canonizados años más tarde y tal fue la importancia de este suceso que en España en 1628 se celebraron en Carmona, un pueblo sevillano, unos festejos donde se conmemoraba su beatificación (Zamora, 2012).

Este periodo de contactos hispano-japoneses se conoce como el Siglo Ibérico. Se caracteriza por el impacto cultural de Occidente en la comunidad japonesa; así como, por la existencia de un intercambio ya que aunque los cristianos se disponían a extender una civilización, se percataron del alto nivel cultural de la sociedad nipona y los trataron como a iguales (Zamora, 2012).

La llegada de los evangelistas europeos a Japón supuso el inicio de un interés especial en aquello que era diferente, en el otro; pero este interés no fue duradero y en pocas décadas se extinguió. A pesar de ello, con este primer contacto con Occidente, Japón inició una época de intercambios culturales, que culminaron en el s. XIX (García Sanz, s.p.) $)^{4}$. Además, este aprecio que Japón presentaba y presenta por la cultura de Occidente la clasifica como una sociedad en la que las artes y la cultura siempre han ocupado un lugar especial dentro del colectivo japonés.

El interés por los japoneses en la cultura occidental se tradujo en un intercambio cultural por medio del comercio de piezas artísticas y religiosas. Los señores feudales japoneses utilizaban los objetos religiosos como complementos de ropa o de cámara y las familias importantes españolas y portuguesas convirtieron las piezas de arte japonesas en objetos religiosos que se siguen conservando en la actualidad en iglesias europeas (García Gutiérrez, 2014).

Este intercambio, además se ve perfectamente reflejado en la creación de un género artístico conocido como Arte Nanban (南蛮nanban significa bárbaros del sur, apodo que recibía los occidentales en Japón) que surge con la llegada de los cristianos al país del sol naciente en el s. XVI, en especial con el misionero jesuita Francisco Javier, antes estudiado. Éste y otros religiosos intentaron difundir la fe cristiana a través de las pinturas religiosas procedentes de España y Portugal (García Gutiérrez, 2014). A partir de este intercambio cultural, muchas fueron las obras creadas por japoneses que copiaron las técnicas artísticas occidentales pero manteniendo los matices artísticos de su propio país. Se creó así un género artístico único, símbolo de las relaciones de Oriente y Occidente (Torralba, 2016).

Por otro lado, en esta pintura no sólo se muestra una presencia cristiana sino además la imagen que tenían los japoneses sobre España y Occidente. El especialista jerezano Fernando García Gutiérrez afirma

\footnotetext{
3 Conferencia titulada "La misión Keicho y la misión Iwakura: precursores en las relaciones internacionales en Japón” impartida por Jesús San Bernardino en Centro Internacional de Postgrado de Sevilla durante la II Semana Cultural de Japón en Sevilla, 8 de noviembre de 2017.

4 Material docente de la asignatura Historia Contemporánea de Asia Oriental, del Grado de Estudios de Asia Oriental de la Universidad de Sevilla, curso 2016-2017.
} 
que Sevilla es la única ciudad española representada en los biombos japoneses, en donde aparecía una descripción del mundo según los japoneses de aquella época (García Gutiérrez, 2008). En las representaciones de esta Sevilla, se puede observar elementos propiamente sevillanos como son la muralla, el río Guadalquivir y por supuesto, una gran construcción que resalta sobre los demás edificios, la Giralda. Este autor cree que los japoneses eligieron Sevilla como protagonista de sus obras ya que en esa época, tal como hemos podido comprobar en el apartado anterior, constituía un puerto importante para las relaciones comerciales (Almazán, 2016).

Aunque este intercambio cultural supuso un hecho importante para la historia japonesa y española, la ruptura con el cristianismo conllevó el fin de este intercambio y el inicio de un supuesto aislamiento en el discurso narrativo occidental. No fue hasta dos siglos después, cuando Japón volvió a tener un contacto continuo y permanente con Occidente; con la llegada de la reforma Meiji en 1868 y la apertura de Japón a Occidente.

\section{Imaginario sobre España y Andalucía creado por Japón}

Adentrarse en cómo las sociedades se piensan a sí mismas e imaginan y representan a las otras con las que establecen una relación, requiere abordarlo con un bagaje teórico y conceptual que lo dote de sentido e inteligibilidad. La antropología social y cultural y los estudios culturales, han dejado una producción especializada que centra su atención en las industrias culturales y la producción mediática de sentido, y sobre la construcción del patrimonio cultural, que permiten una aproximación al tema que nos interesa a partir de la articulación de una serie de conceptos y nociones que necesitamos para abordar la relación entre sociedad-cultura e imaginario construido del mundo. En este imaginario, el patrimonio cultural, en cuanto selección de marcadores simbólicos que transmite una narrativa del nosotros, actúa como representación de la historia compartida, de la pertenencia colectiva y refleja las relaciones y las formas de autorepresentación ante/sobre las otras culturas. La relación entre el patrimonio cultural como producto cultural construido y el imaginario colectivo que permite observarlo como ideología materializada en la acción patrimonialista, es la base desde la que se ha realizado este capítulo.

\section{La influencia de los románticos en la construcción del imaginario}

A continuación estudiaremos cómo surge y se construye el imaginario sobre España en Japón y en otros lugares del mundo. La imagen que posee el colectivo japonés sobre España y Andalucía se caracteriza por la homogeneidad cultural, la inmutabilidad histórica y los estereotipos españoles de fiesta, expresividad y delincuencia que presentan una España muy religiosa y débil política y militarmente (González Troyano, 1987; Gómez, 2011). Estos marcadores culturales proceden en parte de la llegada de los evangelistas a la sociedad japonesa, pero sobre todo por construcciones de un pasado mucho más reciente, por la imagen relatada en las narraciones de los viajeros románticos del s. XIX y en las obras como Carmen (1847) de Prosper Mérimée (1803-1870) o Don Juan Tenorio (1844) de José Zorrilla (1817-1893) que llegaron a Japón en la Reforma Meiji (Gómez, 2011). La imagen de España construida por los románticos no ha sido la única que hace referencia al Estado español pero es la que más difusión ha tenido, llegando a lugares tan lejanos como Japón (González Troyano, 1987).

Los viajeros románticos del s. XIX aparecieron tras el movimiento de la Ilustración con la llegada del romanticismo. El viajero de este movimiento se caracterizaba por la subjetividad y el deseo de evasión del mundo por lo que elementos como la diversidad de paisajes y culturas, el orientalismo, lo exótico, etc... presentaron un gran atractivo. Así surgió el interés por España, convirtiéndose en el "país romántico" por excelencia. Este interés se focalizó sobre todo en Andalucía la cual formó parte de los destinos predilectos, por lo que España fue vista por los románticos desde una perspectiva andaluza (González Troyano, 1987: 17):

"La "polimorfia" andaluza: el conglomerado histórico, la fragmentación y el mestizaje racial, la heterogeneidad geográfica se avenían perfectamente con la sensibilidad poco regulada previamente del romántico".

En esta época, el orientalismo se encontraba en su apogeo. Asia y todo lo oriental era definido por un imaginario occidental marcado por las ideas de poder y superioridad de las potencias occidentales y el exotismo (Said, 1997). Andalucía también fue vista de esta manera, en cuanto fue articulada por su huella histórica en lo oriental del Mediterráneo. Fue relatada como una tierra sublime y espectacular pero llena de gente ignorante y violenta, a quienes se les atribuyó un atractivo especial convirtiéndose en "héroes marginales". De esta manera, los andaluces fueron caracterizados por su astucia, su susceptibilidad, su orgullo, sus celos 
y su ignorancia ya que vivían en una tierra salvaje donde la herencia oriental no había desaparecido. A pesar de esta descripción negativa, los andaluces fueron objeto del poder de recreación de los románticos a través del cual algunas formas andaluzas fueron valoradas como imágenes relacionados con la sensualidad y el tradicionalismo. De esta manera, las figuras del torero, el bandolero y el gitano se convirtieron en marcadores simbólicos de Andalucía y en héroes que remarcaban los "defectos y virtudes de la raza". La bailaora gitana también se convirtió en un tópico importante que representaba la sensualidad y el exotismo, tal como se puede apreciar en el personaje de ficción de Carmen de la obra de Mérimée (González Troyano, 1987). También destacaron mucho la alegría y la gracia del campesinado español, quien, según González Troyano (1987), era considerado por los viajeros como un pueblo libre debido a su relación con la naturaleza y con la agricultura y no subordinado a la fábrica y al trabajo obrero.

Estas fueron algunas de las características que los románticos atribuyeron a España y Andalucía y que recogieron en sus cuadernos de viajes que llegaron a Japón en el s. XIX. En estos relatos el patrimonio cultural andaluz y las ciudades de Sevilla, Córdoba y Granada eran protagonistas. Así surgieron series de ilustraciones gráficas japonesas donde se podían observar La plaza de toros de la Maestranza de Sevilla o la Alhambra de Granada (Almazán, 2016). De esta manera, se fue construyendo la imagen de España y Andalucía que aún hoy en día prevalece. Algunos de los elementos culturales procedentes de la cultura andaluza en los relatos de los románticos tuvieron más calado en la sociedad japonesa que otros, debido a sus características. Este fue el caso del torero ya que en algunos países fue definido como un personaje bárbaro, pero en Japón se asoció al honor y a la hombría (Gómez, 2011).

En realidad, las descripciones de los románticos sobre Andalucía constituyen verdaderos estereotipos relacionados con la tradición y el exotismo. A pesar del paso del tiempo, siguen definiendo la imagen de nuestro país e incluso son fomentados por la misma cultura española, constituyendo además una fuente de autoafirmación de la población andaluza (González Troyano, 1987). El cine y la tv como interfaces ${ }^{5}$ de la cultura de masas, regeneraron este imaginario a mediados del s. XX como muestra Gallardo (2010).

Asimismo, cabe destacar cómo en este imaginario del s. XIX muchos elementos que definen España fueron tomados de la cultura andaluza (Gallardo, 2010; Gómez, 2010), produciéndose una identificación de lo andaluz con lo genéricamente español (Moreno, 1993). Determinadas características culturales de la identidad andaluza han pasado a formar parte del patrimonio cultural español, creando un imaginario de España a través de los distintivos andaluces. El hecho de que España sea eclipsada por Andalucía tiene su origen en la literatura del Siglo de Oro, de la que se nutrieron muchos románticos y en donde Andalucía presentaba un protagonismo especial. A partir de esta imagen relevante de Andalucía y debido a la incapacidad de Andalucía por definir y conocer su identidad, los románticos presentaron una nueva consideración de elementos y marcadores andaluces atribuyéndolos a la imagen de España (González Troyano, 1987).

La incapacidad de autoconciencia que fomenta esta desidentificación, según la teoría esencialista alienadora de Ortega y Gasset (1927 citado en Moreno, 1993), es característica de la cultura andaluza. En esta teoría, se afirma que Andalucía es única y especial pero se caracteriza por la incapacidad de sus integrantes para ser consciente de ella y ser incapaces de fomentarla (Moreno, 1993: 32):

"Vive el andaluz en una tierra grasa, ubérrima, que con mínimo esfuerzo da espléndidos frutos.
Pero, además, el clima es tan suave que el hombre necesita muy pocos de estos frutos para
sostenerse sobre el haz de la vida. Como la planta, sólo en parte se nutre de la tierra y recibe
el resto del aire cálido y la luz benéfica. Si el andaluz quisiera hacer algo más que sostenerse
sobre la vida, si aspirase a la hazaña y a la conducta enérgica, aun viviendo en Andalucía
tendría que comer más y, para ello, gastar más esfuerzo. Pero esto sería dar a la existencia
una solución estrictamente inversa a la andaluza...La famosa holgazanería es precisamente
la fórmula de su cultura. Su solución es profunda e ingeniosa: en vez aumentar el haber,
disminuye el debe; en vez de esforzarse para vivir, vive para no esforzarse, hace la evitación
del esfuerzo principio de su existencia..."

Un ejemplo claro de esta desidentificación se ha producido con uno de los marcadores más importante de la etnicidad andaluza, el flamenco. No hay que olvidar que el flamenco constituye la "expresión social oprimida que han sufrido las clases dominadas andaluzas" (Moreno, 1993). Por ejemplo, solamente la letra de las piezas musicales flamencas, que ha sido transmitida de forma oral, presenta un vocabulario propio del habla andaluza, el cual refleja un contenido etnohistórico sobre memoria histórica de las clases populares andaluzas (Cruces, 2001). A pesar de ello, el flamenco sigue siendo definido como el baile nacional de España.

5 Utilizamos interfaz en el sentido de Manovich (2006) en cuanto la tecnología de la comunicación actúa como interfaz en la transmisión y reproducción de cultura a lo largo de la historia. Y entendiendo como tecnológico todas las formas técnicas en que la cultura se ha comunicado a través de las generaciones, desde la oralidad hasta la web 2.0. 
Esta identificación y el rechazo de la identidad específica andaluza han sido utilizados por el Estado español para negar la existencia de diferentes identidades étnicas nacionales y fomentar la unidad de la cultura española (Moreno, 1993). Esto tuvo su esplendor durante la época franquista. Claro ejemplo de ello, son las películas musicales de los años 30 y 40 donde se muestran claramente la representación que los románticos hicieron de España: ciudades andaluzas rurales, personajes humildes y apasionados, etc... Con estas películas, sobre todo las datadas en los años 40, el estereotipo de lo gitano y lo andaluz representó a España, de modo que se reafirmaba el imaginario ya expandido en el resto del mundo y se hablaba de una España única a lo andaluz (Gallardo, 2010). Esta cuestión cambió con la llegada de la democracia. De esta manera, el artículo 12 del Estatuto de Autonomía dicta como objetivo básico de la comunidad andaluza "afianzar la conciencia de identidad andaluza, a través de la investigación, difusión y conocimiento de los valores históricos, culturales y lingüísticos del pueblo andaluz en toda su riqueza y variedad" (Moreno, 2001). A pesar de ello, esta no es la realidad y ejemplo de ello es el imaginario que Japón posee sobre nosotros.

\section{2, Parque España, y la imagen de España como producto turístico}

España es definida por los japoneses mediante estos marcadores: fiesta, alegría, pasión, tranquilidad, evitación del trabajo, expresividad, poca seguridad, flamenco, gastronomía y cerámica, entre otros. El personaje español se define por ser tradicional, religioso, divertido y perezoso que concuerda con la imagen de los famosos personajes de ficción Carmen y Don Quijote. Los japoneses no observan una heterogeneidad cultural y definen España como un país dividido en regiones entre las cuales destacada Andalucía. Andalucía se identifica como la zona más española donde la tradición no ha desaparecido e inunda todos sus ciudades y a sus gentes (Gómez, 2010).

Estas y otras características que conforman el imaginario japonés sobre España se puede apreciar al analizar diferentes folletos turísticos y guías de viaje. En ellos es apreciable un gran interés en los monumentos sobre todo la Alhambra de Granada, debido a la inclinación por lo exótico que se encuentra en la herencia islámica, y las obras arquitectónicas de Gaudí. Por otro lado, destaca la gastronomía donde la palabra "tapas" y los platos típicos como la tortilla de patatas, el jamón y la paella tienen una presencia importante. Además destacan las flores (claveles y girasoles), las casas blancas de pueblos, lo rural, lo agrario, etc... como formas estéticas características de España. Lo que más se aprecia es la relevancia del flamenco, tanto como espectáculo como modelo estético característico de España, así como, los toros y el fútbol (Gómez, 2011). De igual manera, se fomentan algunos aspectos negativos como la inseguridad y la falta de amabilidad, así como, la imagen de un país sin interés en la ciencia y en la educación (Gómez, 2011).

Las descripciones anteriores nos ayudan a acercarnos al imaginario español que Japón presenta. Teniendo en cuenta los marcadores culturales que engloban la imagen de España para los colectivos, nos vamos a centrar en el parque temático Parque España que constituye una realidad comercial de la imagen de España en Japón. El complejo turístico de Shima Supein Mura 志摩スペイン村, conocido en España como Parque España, surge en 1993 en la prefectura de Mie, cerca del santuario más relevante de todo Japón, el templo de Ise, por lo que se encuentra en uno de los lugares más visitados por el turismo interno en Japón. Nace con el objetivo de presentar a España a los japoneses sin que estos salgan del país (Gómez, 2011).

Lo destacable de este parque es la cantidad de referentes simbólicos sobre España, que surgen a partir del imaginario construido por el colectivo japonés, que presenta. Muchos de estos marcadores culturales se encuentran descontextualizados y no corresponde mucho con la realidad cultural de España sino más bien con el ideal español desde la visión japonesa. Se produce una domesticación de los elementos culturales españoles adaptándolos a los marcadores japoneses. Por ejemplo, en una de las galerías, se expone un traje de novia rojo ya que se vincula este color con España (Gómez, 2011).

Encontramos elementos de diferentes ciudades de España como la famosa Cibeles, la Plaza Mayor de Madrid, el barrio de Santa Cruz de Sevilla, las puertas de la Alhambra de Granada, el Parque Güell; así como, toda una recreación de los pueblos blancos andaluces. Los elementos arquitectónicos más utilizados son las tejas rojas, las fachadas blancas, la piedra y la cerámica. Destaca además, el museo del Castillo de San Francisco Javier (evangelista importante para las relaciones de España y Japón), así como una serie de atracciones como la montaña rusa Corrida de Toros, el Matador y Busca del tesoro de la armada invencible y las mascotas vestidas de torero y flamenca con el nombre Donki (Don Quijote) y Sancho (Gómez, 2011).

Como se puede apreciar, el componente histórico es muy relevante, sobre todo los acontecimientos navales y religiosos del descubrimiento de América, la España árabe y la reconquista, o la Armada Invencible; así como, los símbolos folclóricos que los románticos explotaron en sus relatos. Y por tanto, debido a esta influencia romántica, hay una presencia del patrimonio andaluz que destaca sobre otras comunidades como Madrid y Cataluña de las que se destaca únicamente su monumentalismo. No obstante, como hemos estudiado en el apartado anterior, estos marcadores culturales son observados como españoles y no como propiamente andaluces (Gómez, 2011). 
En el parque aparece una España idealizada e "imaginada" donde el color rojo y las palabras fiesta y alegría envuelven el ambiente. Constituye en definitiva una representación de la imagen de España en Japón, por lo que se podría definir como un producto turístico de exotización temática. La presencia de este parque no solo muestra la presencia cultural de España en Japón sino que además influye en la visión a priori que tiene los japoneses sobre España y Andalucía, alimentando el imaginario creado y promocionado por la propia España (Gómez, 2011).

Al estudiar la existencia de este parque surge una cuestión: por qué este interés en España, ya que existe un parque especial de nuestro país y no sobre otro. A lo largo de la investigación, se ha podido llegar a una respuesta que podría explicar esta relación tan íntima entre países tan diferentes.

Es una realidad que Andalucía presenta una identidad muy remarcada, a pesar de la escasa autoconciencia de sus habitantes, que da lugar a la existencia de un rico legado cultural que se va renovando con el paso de los años pero que recoge la memoria del colectivo andaluz (Gómez, 2010). Por otro lado, Japón presenta un gran interés por la cultura y el patrimonio que se aprecia no sólo en la motivación de los viajes que realiza, la cual se estudiará en el siguiente capítulo, sino además por ser uno de los primeros países en reconocer el patrimonio cultural. Esto se realizó a través de la ley para la Protección de la Propiedad Cultural, mediante la cual se fomenta el respeto al patrimonio tanto material como inmaterial y una conciencia de preservación y protección del patrimonio. En España, como consecuencia de la creación de las autonomías españolas, surge un interés por el Patrimonio Cultural desde 1980 con el objetivo de reafirmar la existencia de las etnias-regionales (Jiménez de Madariaga, 2005). Japón, al igual que España, realizó esto con el fin de proteger la memoria pasada y la identidad nacional que posee en el patrimonio cultural (Agudo, 2016).

Con este hecho, se puede apreciar cómo Japón presenta una inclinación por la cultura y la tradición. Este interés surge a partir de los años 60 cuando se inicia un movimiento por mantener aquellas tradiciones que definen la identidad japonesa para que no sea diluida por la occidentalización y la modernidad. A partir de este momento, surge un interés por los países donde la tradición no haya caído en el olvido y España, como consecuencia del imaginario que se preserva, es uno de ellos. De aquí aparece esta inclinación por España y su cultura en la que Andalucía es la mayor representante (Gómez, 2011: 272):

"La imagen genérica de España (y Andalucía) representa para los japoneses una serie de valores relacionados con "lo tradicional" y "lo exótico" en base a cuestiones como el flamenco, la fiesta, la pasión, la religiosidad y un paisaje rural y/o agrario. Interpretaciones como la falta de educación o la tendencia a evitar el trabajo incorporan un matiz peculiar que parte de la contraposición con la propia cultura japonesa, de manera que "lo español" representa lo diferente y, en cierta medida, la digresión de las normas propias. Sobre esta imagen genérica los turistas japoneses van a añadir los datos relativos a la preparación del viaje, los itinerarios realizados y las imágenes discursivas elaboradas a partir de las fotografías y los souvenirs".

El interés por Andalucía no solo se observa en las guías turísticas, que están llenas de marcadores culturales andaluces, sino además en manifestaciones audiovisuales como en la película titulada Andalucía, la venganza de la diosa que cuenta la historia de un diplomático que intenta resolver un caso de corrupción en Andalucía. Aparecen las ciudades de Sevilla, Jerez y Ronda, pero lo que resalta es la asociación de Andalucía como la región del sol y el amor. En el anime Nasu, verano en Andalucía (primer anime nominado a Cannes) se relata la historia de un ciclista de la Vuelta Ciclista. En este anime se presenta una Andalucía pobre y tradicional en la que destaca el flamenco, la protagonista Carmen y el toro publicitario de Osborne. Además, existe un manga titulado Ryuji cuyo protagonista es un joven futbolista japonés que comienza a jugar en un equipo de segunda B hasta llegar a jugar con el Real Betis Balompié y acabar viviendo en Sevilla. En él, muchas expresiones andaluzas no se traducen y aparecen en romanji como la expresión ¡Viva el Betis manque pierda!, así como, aparece recreada toda la ciudad de Sevilla con sus monumentos más característicos como la Giralda o el barrio de Santa Cruz. En este manga, destaca un sentimiento romanticista y pasional que los románticos ya atribuyeron a los andaluces (Gómez, 2011).

Esta inclinación por Andalucía también se observa en los flujos migratorios, muchos son los japoneses que se trasladan a ciudades de Andalucía como Sevilla y Granada para realizar estudios relacionados con la cultura como las bellas artes o el flamenco.

En el trabajo de campo realizado, se ha mantenido contacto con una de estos japoneses que establecen su residencia en Andalucía. Esta persona cuyo nombre es Keiko Kawabe es la directora de una asociación japonesa de Sevilla. Muchos años antes de la creación de esta organización, esta japonesa comenzó un intercambio conocido como Intership Program en la ciudad de Sevilla ya que en palabras de ella: "estaba interesada en la cultura latina y española". Tras este intercambio, se trasladó de forma definitiva a esta ciudad para "enseñar cultura japonesa en un instituto pues me gusta mucho dar clases a jóvenes estudiantes" según 
sus palabras. Debido a su interés por el arte español, años más tarde, estudió en la Universidad de Sevilla Bellas Artes. Acabó realizando una tesis doctoral y creando la organización cultural Wakei (Kawabe, datos de entrevista) ${ }^{6}$.

\section{Conclusiones}

La investigación desarrollada en este trabajo de investigación comenzó con una cuestión basada en el análisis de la sociedad actual de las comunidades japonesas y andaluzas. Este análisis destacó la existencia de una población japonesa en España y más específicamente en Andalucía, muy relacionada con el mundo cultural de "lo español" y, sobre todo, de un consumo estético, cultural y lúdico del patrimonio cultural andaluz en el seno de la sociedad japonesa. A partir de este hecho, surge la cuestión principal del trabajo: cómo y por qué los japoneses presentan una inclinación muy singular por Andalucía, en la que destaca una especie de exotismo de lo español.

Con este trabajo, se ha demostrado en primer lugar la existencia de este interés particular. Esto se puede observar en la posición que ocupa Andalucía en el ranking turístico japonés, siendo sus ciudades los principales centros de destinos de los turistas japoneses en el país español. España, a su vez, va ocupando un lugar cada más importante en la elección de destinos turísticos por parte del turista japonés. Sin embargo, el hecho que más corrobora este interés por Andalucía se encuentra en la existencia de un parque de atracciones relacionado con España y donde el patrimonio cultural andaluz es el protagonista temático. Lo español se significa a través de lo andaluz.

La existencia de este Parque no sólo demuestra la curiosidad de la sociedad japonesa por nuestro país, sino además, la importancia del patrimonio cultural, sobre todo andaluz, en este interés y por tanto, en las relaciones hispano-japonesas. En el Parque, tal como se ha estudiado, se ofrece como producto de consumo el patrimonio cultural andaluz en forma de atracciones, actividades o decoraciones estéticas. Además de este Parque, la existencia y la relevancia de las actividades culturales fomentadas por organizaciones e instituciones culturales españolas y japonesas relacionadas con el patrimonio cultural español y andaluz confirman el protagonismo de nuestro patrimonio en la sociedad japonesa. El flamenco es la expresión más destacada de estas relaciones. Estos hechos, se vinculan a una patrimonialización de los bienes inmateriales y materiales de la cultura andaluza, fomentada por los organismos de las comunidades estudiadas y representada en las actividades culturales y turísticas que se promueven y han sido analizadas. Por lo tanto, se ha confirmado, que esta patrimonialización desarrolla un exotismo positivo por España y Andalucía que se manifiesta en los discursos y en las prácticas, ya que está vinculado a unas representaciones positivas entre la comunidad japonesa y andaluza que las personas explicitan, y que canalizan un intercambio intercultural, a la vez de un consumo turístico. En definitiva, se fomenta un imaginario construido, en cierto sentido preexistente a nivel institucional político, de índole histórico aunque con cierta continuidad fragmentada, que fomenta los flujos turísticos, culturales y migratorios entre ambas sociedades.

Esta inclinación por Andalucía surge de un establecimiento continuo de relaciones, en el que el patrimonio juega un papel esencial. De este modo forman parte de un patrimonio compartido, las relaciones históricas que se remontan a los siglos XVI y XVII cuando se produce un contacto misionero evangelizador durante la expansión imperial, y las circunstancias en que se retoman en el siglo XIX con la llegada de los románticos a Japón en pleno colonialismo de las potencias industriales. Pero en la globalización, el interés por España y Andalucía, surge a partir de los años 60 cuando los japoneses centran su atención en la búsqueda de la esencia japonesa, con el objetivo de no perderla, superada la crisis de posguerra y la reconstrucción, en el contexto discursivo político del surgimiento de un mundo nuevo que caracterizó los 70 . Fruto de ello, aparece una curiosidad por la tradición y por ello, por los países en dónde ésta prevalece. España será un enclave de este reflejo, como consecuencia del imaginario romántico por la visión eurocéntrica, y Andalucía, la parte que encarnará lo más "tradicionalmente español".

A partir de todos estos resultados que evidencian una relación íntima de lo estético entre los japoneses y Andalucía, se abre la puerta a una revaloración de las relaciones entre ambas sociedades que vayan más allá de un imaginario creado y se centre en la promoción de ese interés por el patrimonio cultural de ambas sociedades, de forma que un enriquecimiento intercultural de las relaciones fortalezca relaciones económicas, tecnológicas, científicas y culturales de las que se beneficien ambos extremos.

\section{Bibliografía}

Agudo, J. (2016) "La valoración del patrimonio material en España y Japón. Una breve reflexión comparativa" en Gómez, A. Japón y Occidente. El patrimonio Cultural como puente de encuentro. Se-

6 Material de entrevista, 28 de marzo de 2018, Sevilla. 
villa: Aconcagua Libros. Disponible en: https://dialnet.unirioja.es/servlet/libro?codigo=654205 [Acceso: 2/03/2018].

Almazán, D. (2016) "El patrimonio cultural andaluz en la construcción de la imagen de España en el Japón de la era Meiji (1868-1912). De las primeras representaciones al japonismo de Julio Romero de Torres" en Gómez, A. Japón y Occidente. El patrimonio Cultural como puente de encuentro. Sevilla: Aconcagua Libros. Disponible en: https://dialnetunirioja.es/servlet/libro? codigo=654205[Acceso: 2/03/2018].

Caddell, C. (1904). The Cross in Japan: a history of the missions of St. Francis Xavier and the early Jesuits. Londres: Burns and Oates.

Cruces, C. (2001). "El flamenco y la identidad andaluza" en Cano, G. La identidad del pueblo andaluz. Sevilla: Defensor del Pueblo Andaluz.

García Gutiérrez, F. (2014). "Introducción y desarrollo del arte occidental en Japón en el siglo XVI y XVII" en Gómez, A. Japón y su relación con Occidente. Conmemoración de los 400 años de relaciones España-Japón. Sevilla: Universidad Internacional de Andalucía.

Gómez, A. (2010). "La imagen de Andalucía en el turismo cultural: el caso de Japón” en Jiménez-Caballero, J.L.; De Fuentes, P. (coord.) Nuevas perspectivas del turismo para la próxima década: III jornadas de investigación en turismo. Sevilla: Edición Digital@tres.643-663. Disponible en: https:/idus. us.es/xmlui/bitstream/handle/11441/53142/gomezaragon.pdf?sequence=1[Acceso: 2/03/2018].

Gómez, A. (2011). "Interpretaciones mutuas España y Japón: imágenes construidas” en Cid, F. Japón y la península ibérica, cinco siglos de encuentros. Gijón: Satori Ediciones. Gómez, A. (2010). "La imagen de Andalucía en el turismo cultural: el caso de Japón” en Jiménez-Caballero, J.L.; De Fuentes, P. (coord.) Nuevas perspectivas del turismo para la próxima década: III jornadas de investigación en turismo. Sevilla: Edición Digital@tres.643-663. Disponible en: https://idus.us.es/ xmlui/bitstream/handle/11441/53142/gomezaragon.pdf?sequence=1 [Acceso: 2/03/2018].

González Troyano, A. (1987). La imagen de los viajeros románticos y Homenaje a Gerald Brenan, Málaga: Diputación Provincial de Málaga.

Jiménez de Madariaga, C. (2005). "Patrimonio etnológico e instrumentación política" en Sierra, J. C; Pereiro, X. Patrimonio cultural: politizaciones y mercantilizaciones: X Congreso de Antropología. Sevilla: Fundación El Monte.25-36. Disponible en: https://www.researchgate.net/publication/316 154881PATRIMONIOETNOLOGICOEINSTRUMENTACION_POLITICA [Acceso: 2/05/2018].

Moreno, I. (1993). Andalucía: identidad y cultura (estudios de antropología andaluza). Málaga: Ágora. Moreno, I. (2001). "Política cultural, política económica e identidad andaluza" en Cano, G. La identidad del pueblo andaluz. Sevilla: Defensor del Pueblo Andaluz.

Moreno, I. (2001). "Política cultural, política económica e identidad andaluza" en Cano, G. La identidad del pueblo andaluz. Sevilla: Defensor del Pueblo Andaluz.

Said, E.W (2003) Orientalismo. Barcelona: DeBolsillo.

Torralba, E. (2016) "Retratos Nanban: delicadas líneas que perfilan la sorpresa de descubrir un nuevo rostro" en Gómez, A. Japón y Occidente. El patrimonio Cultural como puente de encuentro. Sevilla: Aconcagua Libros. Disponible en: https://dialnet.unirioja.es/servlet/libro?codigo=654205 [Acceso: $2 / 03 / 2018]$.

Valignano, A. (1954) "Sumario de las cosas de Japón 1592; Adiciones del Sumario de Japón 1593" en Monumenta Nipponica monographs, no. 9. Tokyo: Sophia University.

Zamora Calvo, M. J. (2012) Japón y España: acercamientos y desencuentros. Gijón: Saitori Ediciones. 坂東省次, 川成洋編 (2010). 日本・スペイン交流史.東京. 